\title{
Analyzing population ageing and intergenerational redistribution: NTA and AGENTA
}

\author{
Ronald Lee $^{1, *}$ and Andrew Mason ${ }^{2}$
}

This special issue of the Vienna Yearbook contains chapters derived from the EUfunded AGENTA project, which uses and extends the methods of the National Transfer Accounts (NTA) project to shed light on the ways in which the families and governments of Europe draw on the earnings of the working-age population to support both children and the elderly. Before turning to the fascinating studies included in this Yearbook, we will provide some context regarding support systems, global demographic change, NTA, and AGENTA.

\section{Support systems}

The market economy allocates incomes to individuals according to their contributions to production through working or investing. But although children neither work nor invest, they have consumption needs. While some elderly people work and can depend partly on their savings, these resources are insufficient to meet their consumption needs in many countries. The gap between consumption and labor and asset income is filled through public and familial support systems that reallocate income from people who work and hold wealth to the young and the old. We call these reallocations "intergenerational transfers." Unlike market exchanges, these transfers are much like gifts, as they come with no explicit quid pro quo. The support systems of countries vary. Across countries, we see differences in the mix of public and private transfers to the young and the old, the degree to which the elderly generate labor and asset income, and the consumption needs of children and the elderly. Over the course of a country's economic development, there tends to be a shift away from relying on family-based support systems and toward relying

\footnotetext{
${ }^{1}$ Departments of Demography and Economics, University of California, Berkeley, USA

${ }^{2}$ East-West Center and University of Hawaii at Manoa, Honolulu, Hawaii, USA

${ }^{*}$ Correspondence to: Ronald Lee, rlee@ demog.berkeley.edu
} 
on the public sector to provide support through public pensions, health care, and education.

\section{Global demographic change}

Over the past 200 years, the populations of the world have been experiencing a process that has been called the "demographic transition." This term refers to a period of demographic change during which a population undergoes a transition from having high fertility and high mortality to having low fertility and low mortality. Typically, this change is initiated by mortality decline, particularly at young ages. This decline causes an acceleration of population growth, an increase in the share of children in the population, and a rising ratio of dependents to workers. This stage is soon followed by a decline in fertility, which ushers in many decades of slowing population growth and falling dependency ratios. These developments generate a so-called "demographic dividend," which boosts economic growth. The dividend phase ends when fertility levels off, survival rates at old ages increase, and the share of elderly in the population begins to rise. These developments lead to a long phase of rising dependency ratios and population aging. Moreover, these changes in a country's population age distribution interact with its support system. They generate benefits or stresses, depending on whether the numbers of people who are at ages when transfers to others are usually made grow or shrink relative to the numbers of people at ages when transfers are typically received. The economic consequences of these changes can be quite significant, and can give rise to enthusiastic hopes while the country is enjoying a demographic dividend, and to grave concerns while the country is experiencing population aging. How can we better understand these consequences, assess them in advance, and develop policies that influence and accommodate population change? How realistic are widely held perceptions about the consequences of the changing age structure?

\section{National Transfer Accounts}

The NTA project has produced a set of rigorous and consistent methods for measuring the flows of resources to and across ages and generations through the market, the family, and the public sector. The NTA framework provides a detailed numerical description of the support system of each country. These methods have been described and applied in Lee, Mason et al. (2011), and are presented in detail in a UN manual (United Nations 2013). The NTA project does not carry out any special surveys. Rather, it uses existing data sources, such as surveys, censuses, National Accounts, and administrative data. A distinctive feature of the NTA project is that it applies the same methods to all countries, regardless of whether they are rich and poor, are in the pre-transition or the dividend stage, or are experiencing population aging. This framework makes comparative analysis possible. 
The international NTA project was launched by Lee and Mason in 2004, initially together with collaborators in seven countries. By 2019, the project had grown to include research teams in more than 60 countries distributed across Europe, North America, South America, Africa, Asia, and Oceania. A project website (http://ntaccounts.org) serves as a repository for the accounts generated for the countries, secondary measures generated using NTA data, working papers, and many other aspects of the project. NTA have been used extensively to study the demographic dividend, the consequences of population aging, and the support systems themselves. The organization of the project is decentralized, with each continent having a regional leader; though the core governing functions of the project are based at the East-West Center in Hawaii and at the University of California at Berkeley.

Over the past decade, the NTA framework has been extended in important ways. These include breaking down NTA by socioeconomic status; using NTA to study generational wealth; and constructing longitudinal NTA using multiple surveys going back in time. Of particular importance for this Yearbook is the extension of NTA to include "time transfers" based on the analysis of time use surveys. This extension permits the construction of NTA by gender, including time spent caring for children and the elderly, and on activities such as cooking, cleaning, shopping, home repair, and household administration. When the NTA framework includes the time/gender accounts, it is called National Time Transfer Accounts, or NTTA. Given that in most - or possibly all - societies women do the majority of work in the home, it would not make sense to construct NTA by gender without including home production. In the NTTA framework, the productive use of time in the home is valued according to its cost in the labor market, which is assessed by referring to the cost of hiring either a generalist housekeeper or, more typically, a worker to perform each type of activity, such as caring for children or preparing a meal. If a household member prepares a meal for a family of three, the cost (including time cost) of the meal is allocated to all three members, including the preparer. It is assumed that the preparer is making time transfers to the others, but not of the full time spent preparing the meal, since part of the time is consumed by the preparer him/herself.

\section{AGENTA}

The AGENTA project (http://www.agenta-project.eu) was started by the leadership of the European NTA: namely, Alexia Prskawetz (Austria), Hippolyte d'Albis (France), Robert Gál (Hungary), Agnieszka Chlon-Dominczak (Poland), Jože Sambt (Slovenia), Concepció Patxot (Spain), Tommy Bengtsson (Sweden) and David McCarthy (UK). These scholars successfully applied for four-year funding for the project from the European Union. AGENTA uses the NTA approach and NTA methods to describe and analyze the support systems in the countries of Europe, and to assess and project the consequences of population aging. One important task of this project has been to estimate the accounts based on harmonized 
data from Eurostat. Such estimates were eventually generated for 26 of the 28 countries in the EU. Before this could be done, each country team estimated its NTA using the particular data available for that country. It is likely that this effort to create a harmonized regional dataset will remain unique within the NTA project, since in no other region of the world are the countries as closely knit as they are in Europe, which has a shared statistical agency. Interestingly, comparisons of these harmonized AGENTA estimates with those based on each country's own data have sometimes revealed discrepancies. Nonetheless, the harmonized NTA have permitted the extension of the accounts beyond the dozen or so EU countries that have teams. The broad, harmonized base of European NTA data can be used for comparative analysis, as we will see in some of the papers in this Yearbook. The project completed its work and ended with a conference in Vienna in December of 2017. Earlier versions of many of the papers in this volume were presented at that meeting.

With that background in mind, we can now turn to describing the chapters in this Yearbook. The chapter by Sánchez-Romero, Abío, Botey, Prskawetz, Sambt, Juvés, Souto, Vargha, and Patxot uses a computable OLG model with realistic demography to assess the consequences of population aging, while drawing on both NTA and NTTA. The results of this analysis show that without policy changes, there will be a large increase in the share of GDP going to public transfers. In their comparison of transfers in Spain, Austria, and France, they find that the public sector in Spain redistributes the most income to older individuals, while Austria redistributes the least. They simulate two policy options for coping with the fiscal pressures of population aging: raising the retirement age, which effectively reduces benefits for the elderly; and raising taxes, which effectively increases the transfer of income from working-age adults to the elderly.

The chapter by d'Albis and Badji assesses gender and intergenerational inequalities in France using a measure (i.e., the mortality-adjusted disposable income), which reflects both length of life and income. They find that although this measure has increased substantially over time, its growth is entirely due to increases among women, while progress among men has stagnated for the generations born after 1946.

The chapter by Chlon-Dominczak, Abramowska-Kmon, Kotowska, Łątkowski, and Strzelecki uses the harmonized NTA to investigate the welfare state typologies in the literature and the differences in welfare state structures across the EU. They find that countries fall into one of three groups: most of the countries in the middle are quite similar; but the Scandinavian countries plus Luxembourg have more generous public transfers, particularly to the elderly; while some of the Central and Eastern European countries have less generous transfers. As we discussed above, population aging interacts with the support system - which in this context is the welfare state - to exacerbate or to relieve fiscal pressures. But how does the state respond? An important finding in this paper is that the Scandinavian countries tend to raise taxes and maintain benefit rates in the face of population aging, while Central and Eastern European countries tend to cut their benefits. We don't know 
how countries will respond to aging in the future, but this chapter shows us two of the possible paths.

In Sweden, raising the retirement age has been the main strategy for meeting the challenges of population aging due to rising life expectancy, according to the paper by Bengtsson, Qi, and Scott. They describe how increases in the retirement age affected different social groups in the Swedish population from 1980 to 2011.

Several of the chapters use NTTA and time transfer data to address a range of questions. A chapter by Šeme, Vargha, Istenič, and Sambt looks at the age patterns of unpaid household work by gender, and at how these patterns have changed over time. They find that although these trends differ by gender, certain patterns remain the same: i.e., time transfers are mainly from women to men, and from the workingage population to children and - albeit to a lesser extent - to the elderly.

One important question, which is addressed in the chapter by Zannella and De Rose, is how the recent recession affected time use and time transfers. They find that it was not until the recession reduced the market work hours of men that the hours of unpaid work performed by men in the home began to increase.

A chapter by Dukhovnov and Zagheni analyzes time transfers in the U.S., and examines how these transfers differ across population subgroups. They also introduce a new measure, the Care Support Ratio (CSR), which indicates how household time budgets vary depending on household composition. They use this measure to show that population aging in the U.S. will put pressure on informal care giving.

Taken together, these seven papers illustrate the wide range of topics and approaches that can be drawn from the NTA.

Finally, the last contribution in the data section summarizes the basic principles and data used to set up the European National (Time) Transfer Accounts, and illustrates the age profiles of selected variables for the EU-25 average. 